Portland State University

PDXScholar

7-16-1984

\title{
Effect of Menstrual Cycle on Hedonic Response to Gustatory Stimuli
}

\author{
Laurie Ann O'Toole \\ Portland State University
}

Follow this and additional works at: https://pdxscholar.library.pdx.edu/open_access_etds

Part of the Biological Psychology Commons, and the Reproductive and Urinary Physiology Commons Let us know how access to this document benefits you.

\section{Recommended Citation}

O'Toole, Laurie Ann, "Effect of Menstrual Cycle on Hedonic Response to Gustatory Stimuli" (1984). Dissertations and Theses. Paper 3390.

https://doi.org/10.15760/etd.5271

This Thesis is brought to you for free and open access. It has been accepted for inclusion in Dissertations and Theses by an authorized administrator of PDXScholar. Please contact us if we can make this document more accessible: pdxscholar@pdx.edu. 
TO THE OFFICE OF GRADUATE STUDIES AND RESEARCH

The members of the committee approve the thesis of Laurie A. O'Toole presented July 16, 1984.

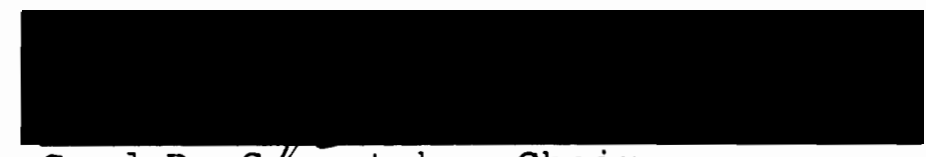

cord B. słngstake, Chair

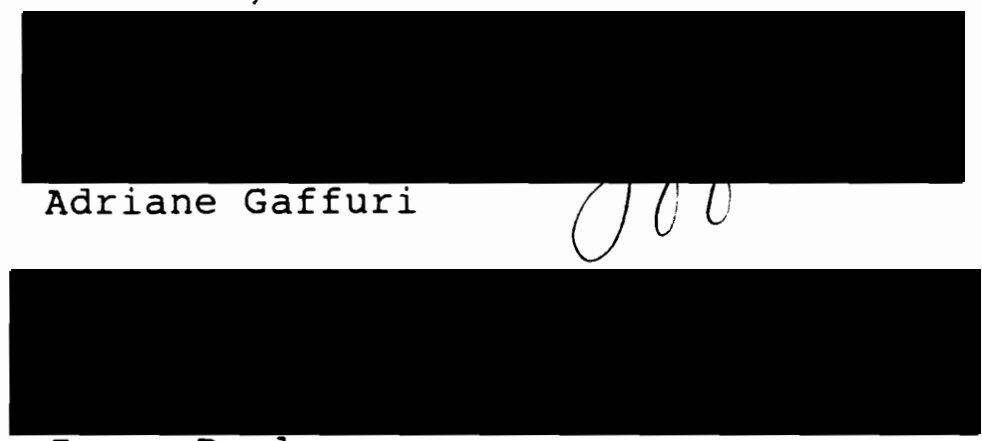

James Paulson

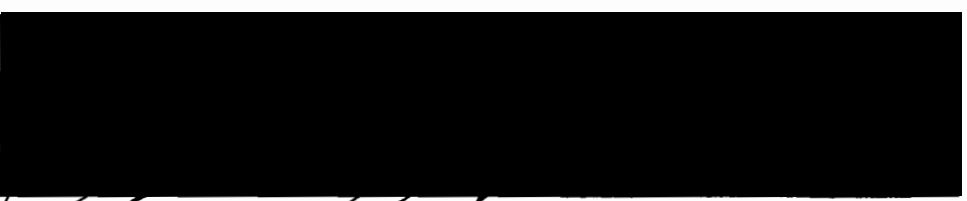

Eester J. Newnan

APPROVED :

Rogg1 Jennikg f, Head, Deparfment of Psychology 
EFFECT OF MENSTRUAL CYCLE ON HEDONIC RESPONSE TO GUSTATORY STIMULI

by

LAURIE ANN O'TOOLE

A thesis submitted in partial fulfillment of the requirements for the degree of

\section{MASTER OF SCIENCE \\ in \\ PSYCHOLOGY}

Portland State University 
AN ABSTRACT OF THE THESIS OF Laurie Ann O'Toole for the Master of Science in Psychology presented July 16, 1984 .

Title: Effect of Menstrual Cycle on Hedonic Response to Gustatory Stimuli.

APPROVED BY MEMBERS OF THE THESIS COMMITTEE:
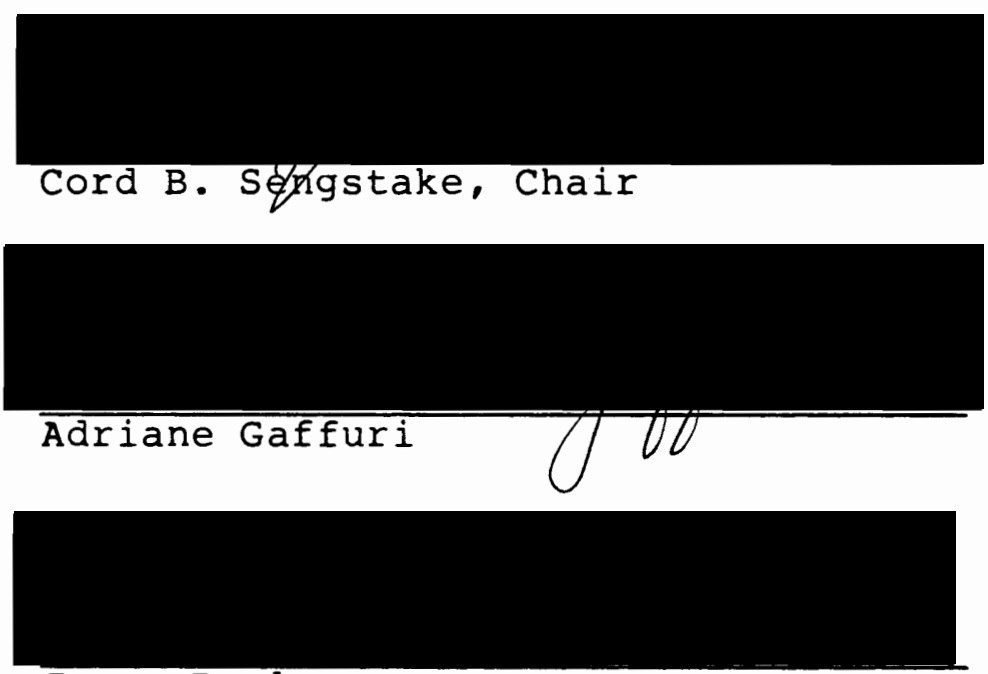

James Paulson

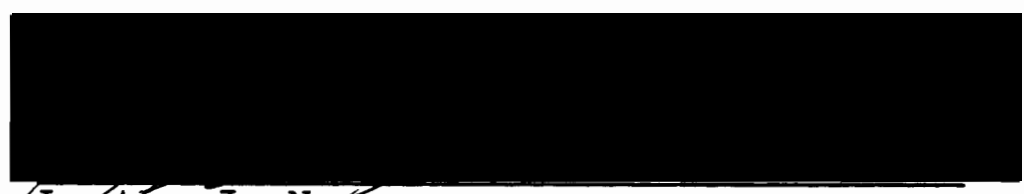

Lester J. Newman

The present experiment was conducted to determine the relationship between the human menstrual cycle and gustatory hedonic response. Hedonic response was defined as the perceived pleasantness or unpleasantness of a taste 
stimulus. Gender differences in taste hedonic have been observed; these may be due to differences in endocrine systems. Animal taste preferences are altered when reproductive hormonal status is experimentally manipulated. Previous researchers report that human females' hedonic responses to sucrose vary systematically with phase of menstrual cycle.

In the present experiment, normally cycling women were tested at one of five phases of the menstrual cycle. Seven concentrations of each of four kinds of taste stimuli were evaluated. A seven-point rating scale (from +1 -- very unpleasant to +7 -- very pleasant) was used to quantify hedonic response. Taste stimuli were aqueous solutions of sucrose, citric acid, sodium chloride, and quinine monohydrochloride. Hypotheses were: 1) that women tested in luteal phase would produce a different profile of hedonic response to sucrose, sodium chloride, and quinine than would women tested in other phases; and 2) that Preovulatory group women would differ from those in Premenses group in their hedonic responses to citric acid.

Results of this study showed that concentration of the stimulus solution interacted with phase of menstrual cycle to produce significant group differences in profiles of hedonic response to sucrose and citric acid solutions. Luteal group women differed from those in Premenses and Preovulatory groups in their hedonic response to sucrose. 
As expected, Preovulatory group and Premenses group significantly differed from each other in their hedonic responses to citric acid solutions. No effects of menstrual cycle phase on the perceived pleasantness of sodium chloride or quinine solutions were obtained in this experiment.

Hedonic responses to sweet and sour taste stimuli are functionally related to some menstrual cycle variable. The present experiment did not directly examine a mechanism by which a menstrual cycle variable could affect gustatory sensory function. 


\section{ACKNOWLEDGEMENTS}

An experiment was conducted to determine if a graduate student subject would respond to an extensive range of stimuli by designing and carrying out an independent research project. Principal investigators were Cord B. Sengstake, Adriane Gaffuri, and James Paulson. Stimuli were a knowledge of physiologcal psychology and statistics, research ability, and patient encouragement. Adjunct stimuli were erudite criticism provided by Larry Crawshaw and genetic material provided by Lester J. Newman. Significant results were obtained in this lengthy experiment. The subject reports robust sensations of gratitude and respect for all investigators. 
TABLE OF CONTENTS

PAGE

ACKNOWLEDGEMENTS........................ ii

LIST OF TABLES......................... vi

LIST OF FIGURES....................... vii

CHAPTER

I INTRODUCTION..................... 1

Physiology of Gustation.............. 1

Gustatory Stimulus Composition

Other Factors Affecting Gustation

Gender Differences in Taste Perception.... 5

Animal Taste Preference Data.......... 7

Physiology of the Menstrual Cycle....... 10

Menstrual Phase

Preovulatory Phase

Ovulatory Phase

Luteal Phase

Premenstrual Phase

Menstrual Cycle Effects on Taste

Perception.................... 14

Statement of Hypotheses.............. 19

I I METHOD......................... 23

subjects...................... 23 
PAGE

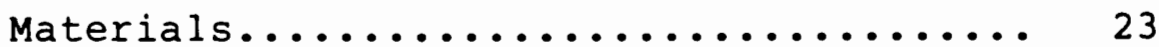

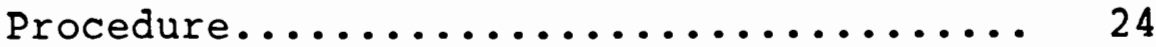

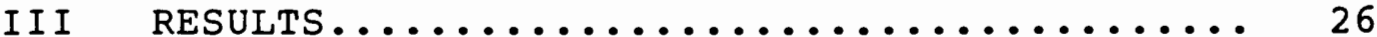

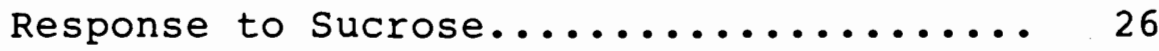

Response to Citric Acid.............. 32

Responses to Sodium Chloride and Quinine. 36

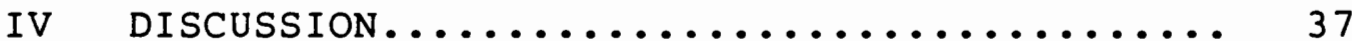

Response to sucrose................. 37

Comparison of Research Outcomes

Response to Citric Acid............... 40

Responses to Sodium Chloride and Quinine. 42

Methodological Considerations.......... 43

Mechanisms of Gustatory-Endocrine

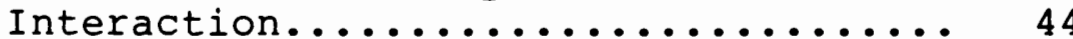

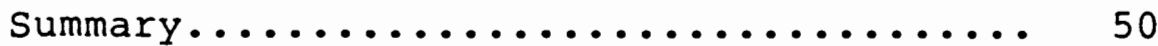

Future $\operatorname{Research} \ldots \ldots . . . . . . . . . . . .50$

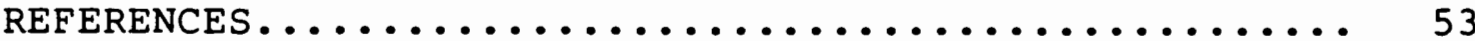

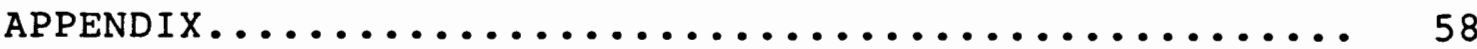




\section{LIST OF TABLES}

TABLE

PAGE

I Coefficients of Each Molarity of Sucrose on the Significant standardized Linear

Discriminant Function............... 30

I Coefficients of Each Molarity of Citric

Acid on the Significant Standardized

Linear Discriminant Function........... 


\section{LIST OF FIGURES}

\section{F IGURE}

PAGE

1. Plasma Levels of Estradiol and

$$
\text { Progesterone. }
$$

2. Mean Pleasantness Ratings Assigned to

Sucrose Solutions by Menstrual Cycle

Phase Groups.

3. Mean Pleasantness Ratings Assigned to

Citric Acid Solutions by Menstrual

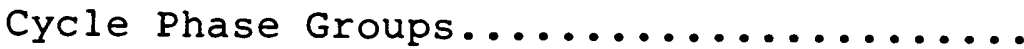




\section{CHAPTER I}

\section{INTRODUCTION}

\section{Physiology of Gustation}

The human gustatory sensory system functions to identify nutritive substances and is involved in the regulation of their intake. The structure and function of gustatory receptor cells are primary factors in taste perception. The organs of taste are the taste buds, which consist of 40 to 50 clustered receptor cells, each with many projecting microvilli. These receptor cells are associated with specialized papillae on the epithelial covering of the tongue; they are also found on the soft palate, pharynx, and larynx. The branches of a single nerve fiber serve several taste buds, and thus, many cells. Individual taste cells function for about eight days. They then degenerate and are replaced by daughter cells from the surrounding lingual epithelium. Gustatory nerve endings within the buds must also divide continuously and rapidly to innervate individual receptor cells.

Gustatory nerve transduction occurs when a chemical stimulus forms a weak electrostatic or hydrogen bond at the surface of the microvilli of the taste cells, which project into the salivary coat. This bonding elicits a change in membrane permeability at the base of the taste cell. If 
the change in permeability is sufficient, a neural impulse will be produced. Gustatory receptor cell activity elicits four primary taste sensations which are sweet, sour, bitter, and salty. Taste stimuli may be classified according to the sensations they can produce. Sweet, sour, bitter, or salty tasting substance will be referred to in the present study as taste qualities. Individual taste cells respond differentially to these four primary kinds of stimu1i. Circumvallate taste buds on the dorsal surface of the tongue respond primarily to bitter stimuli; the fungiform taste buds on the ventral anterior surface are most sensitive to sweet and salty substances. Neural coding for taste differentiation may occur at the level of the gustatory nerve fiber. It has been shown that a single taste fiber can respond to several kinds of chemical stimuli, as well as to thermal and electrical stimulation. However, taste fibers can be grouped according to a primary taste quality to which they respond best (Beidler, 1980).

Afferent nerve fibers from gustatory receptor cells project to structures in the midbrain and forebrain, including at least three areas of the cortex. Primary afferent nerve pathways for gustation are the chorda tympani, facial, vagus, and glossopharyngeal nerves. These fibers synapse in the brain stem and send third order neurons to the ventral posterior thalamus, hypothalamus, limbic system and medulla. The central nucleus of the amygdala receives 
gustatory afferents. Some neurons in this nucleus show a selective response to specific taste stimuli (Schwartzbaum \& Morse, 1978). Cortical regions involved in taste sensation and perception are the parietal, anterior opercularinsular and ventral somatosensory cortices (Carlson, 1982). Gustatory Stimulus Composition. Taste receptor cell activity is most frequently initiated by chemical stimulation. The nature of a perceived gustatory stimulus is highly dependent upon its molecular configuration and behavior. Substances which can act as taste stimuli are ions and a variety of neutral organic and inorganic molecules. Receptor cells can respond to these chemicals over a wide range of concentrations. Sugars, glycols, and some other organic compounds are perceived as sweet tasting by humans. A small change in molecular shape can transform a sweet substance to a bitter one. Alkaloids and some long-chain organic molecules taste bitter. The presence of hydrogen ions is a necessary condition for perception of a sour taste. Sodium chloride produces a pure salt taste in humans while other ionic salts elicit a mixture of taste sensations. Perceived intensity of a gustatory stimulus depends upon its aqueous concentration and upon the electrical status of the receptor membrane (Guyton, 1976).

Other Factors Affecting Gustation. Genetic influences on human taste perception have been investigated. The ability to taste certain bitter substances such as 
phenylthiocarbamide is genetically determined. Presumably, a gustatory cell membrance receptor site is altered (Jenkins, 1983). Researchers have examined the gustatory behavior of newborn infants and of twins for a heritable component. In newborns, a preference for sweet tastes has been consistently observed. Desor, Maller, and Turner (1973) reported that newborns could discriminate between water and any of four sugar solutions. When offered water and a sugar solution for three-minute periods, infants ingested more sugar solution. In a subsequent study (Desor, Maller, \& Andrews, 1975) newborns were given sucrose and sucrose plus urea, citric acid, or sodium chloride. In 3-min. trials, infants suppressed intake of the sucrose/ citric acid solution relative to sucrose alone. Infants did not suppress intake of the sucrose/urea or sucrose/sodium chloride mixtures. Greene, Desor, and Maller (1975) measured taste preference in 9- to 15-year-old monozygotic and like-sex dizygotic twin pairs. Children were asked to order solutions of sucrose, lactose, and sodium chloride from most to least preferred. A very low concordance rate in preferred concentration of all taste stimuli was found. These researchers concluded that heritable taste preferences can be modified by early experience.

Human taste perception can be affected by an individual's metabolic state, and by sensory properties of the taste stimulus. For example, Vasquez and her co-workers 
(1982) compared the amount of sucrose solution ingested by malnourished and well nourished infants in a free-feeding test. Malnourished infants consumed less of the sucrose. Pleasantness ratings assigned to a sweet stimulus declined after healthy adults consumed small preloads. This pleasantness reduction was greatest for subjects given a preload that was high in calories (Scherr \& King, 1982). Rolls, Rowe, and Rolls (1982) reported that color and shape of the stimulus systematically affected pleasantness ratings given to foods. Other stimulus variables which alter taste perception and preference are odor, texture, and temperature (Atkinson, Atkinson, \& Hilgard, 1983).

\section{Gender Differences in Taste Perception}

Researchers have examined such dimensions of taste perception as recognition thresholds, detection thresholds, and preferred concentrations of taste stimuli; some gender differences have been obtained with human subjects. In recognition threshold experiments, subjects are asked to identify taste stimuli as being sweet, sour, bitter, or salty. Bailey and Nichols (1888) measured recognition thresholds for bitter, sweet, acid, alkaline (sodium bicarbonate) and saline tastes. Females were able to correctly identify lower concentrations of all taste stimuli except saline. Soltan and Bracken (1958) investigated adult subjects' abilities to identify four primary taste qualities. 
Fifty males and fifty females were tested weekly for 12 consecutive weeks. Females were more consistent than males in response to two bitter tasting compounds, quinine sulfate and sodium benzoate. No gender differences were obtained for response to sucrose, sodium chloride, citric acid, or phenylthiocarbamide. Pangborn (1959) reported that recognition thresholds for sucrose, sodium chloride, citric acid, and caffeine were all lower in females than in males.

A detection threshold for a taste stimulus solution is the lowest concentration at which it can be reliably differentiated from water. Some detection threshold experiments report a gender difference in human subjects while others do not. Pangborn (1959) measured detection thresholds for four tastants. Females were more sensitive than males to all stimuli. Fergenson, Moss, Dzendolet, Sawyer, and Moore (1975) used a signal detection procedure to measure detection threshold for sucrose in 24 males and 24 females. No gender differences in taste sensitivity were observed. Kunka, Doty, and settle (1981) found no gender differences in detection thresholds for low concentrations of surcrose. Coats measured gustatory sensitivity by applying electrical current to the tongues of male and female subjects. This form of stimulation generates a metallic taste. Females reponded to lower intensities of the electrical stimulus than did males. In an extensive review of 
the literature on gender differences in taste perception, Doty (1978) concluded that "more such studies, using a variety of taste stimuli, are needed before it can be definitely stated that females are more sensivite than males to taste stimulation" (p. 343).

Gender differences in hedonic response to gustatory stimuli have been observed. Greene, Desor, and Maller (1975) investigated preference for various concentrations of sucrose, lactose, and sodium chloride using a rank-ordering procedure. Among 9- to 15-year-olds, males selected sweeter sucrose solutions as most preferred than did females. Caucasian but not black males preferred more concentrated lactose solutions than did females. No gender difference was observed in an identical procedure with 140 adult subjects (Desor, Greene, \& Maller, 1975). According to Doty (1978) "the available evidence suggests that men and women differ in their reported taste preferences to strong concentrations of certain sweet-tasting stimuli" ( $p$. 347). Doty has described potential physiological and psychological factors which could explain observed gender differences.

\section{Animal Taste Preference Data}

Endocrine systems having interaction with systems of gustation could account for gender differences in taste perception. Researchers using animal models have found an 
apparent functional relationship between taste perception and levels of ovarian hormones. In an extensive review, Wade (1976) discussed gustatory responses in prepubertal, normally cycling, ovariectomized, and pregnant rats. Prior to puberty, both male and female rats reject sweet liquids. Intact adult females exhibit a preference for saccharin, a nonnutritive sweet substance. Normally cycling females also show an aversion to bitter substances such as quinine. These responses are affected by gonadal hormones.

In order for female rats to exhibit saccharin preference, testosterone must be absent during the neonatal period and estrogen plus progesterone must be present in adult animals. Neonatal female rats given a single injection of testosterone propionate show reduced saccharin preference in adulthood when compared with untreated females (Wade \& Zucker, 1969). Ovariectomized adult females exhibit a diminished saccharin preference; when estradiol benzoate plus progesterone are given by injection, normal taste responsiveness is restored. Neither hormone given alone restored saccharin preference to ovariectomized females (Wade \& zucker, 1970). In pregnant or pseudopregnant rats, progesterone levels are high relative to estrogens. These animals exhibit much decreased saccharin preference when compared with normally cycling animals.

In two experiments, Dippel, Elias, and Yandell (1983) studied the effects of exogenous hormones on gustatory 
responses of intact female rats. In the first experiment, animals received daily injections of $5 \mu \mathrm{g}$ of one of three synthetic progestins plus $0.25 \mu \mathrm{g}$ or $1.25 \mu \mathrm{g}$ of ethinyl estradiol. Dosages were selected to approximate the hormonal status of human females using oral contraceptives. Intake of a 0.758 saccharin solution was measured in a twobottle test. Estradiol plus any synthetic progestin suppressed preference for saccharin. Norgestrel, which is biologically active as a true progestin, was most effective in this regard. In a second experiment, progestins were given in the absence of estradiol. This produced no suppression of sweetness preference. When $1.25 \mu \mathrm{g}$ of ethinyl estradiol was given alone, sweetness preference diminished to a lesser extent than was observed with hormones in combination.

Both estrogen and progesterone must be present in order for adult females to show aversion to quinine. Ovariectomized animals will drink mnore of a quinine solution than will intact animals. Estrogen plus progesterone must be given by injection to restore quinine aversion. Pregnancy or pseudopregnancy produces a reduction in quinine aversion (Wade \& Zucker, 1970).

Responsiveness to sodium chloride is altered only when gonadal hormone levels are experimentally manipulated within the first few days of birth. Kreček and his co-researchers found that intact adult female rats will consume 
more of a 38 soldium chloride solution than will males. When animals were gonadectomized at age 10 days, this sex difference in taste response was unaffected. However, a single injection of testosterone propionate at age two days suppressed response differences; females adopted a male pattern of saline intake (Křeček, Nováková, \& Stibral, 1972; Křeček, 1973).

Animal work has shown that manipulation of reproductive hormone levels in adult female rats alters their responses to sweet and bitter, but not salty substances. Estrogens are a primary determinant of hedonic response to sweet and bitter tastes; progestins exert a modulating effect. Wade (1976) has hypothesized that "these hormones act on hypothalamic or limbic sites to alter the reinforcing properties of tastes" (p. 258).

Physiology of the Menstrual Cycle

Research with human subjects indicates that perceived intensity and pleasantness of gustatory stimuli may be mediated by female reproductive hormones. These components of taste perception vary across the repoductive cycle. In all primates there is a menstrual cycle consisting of proliferation, secretion, and desquamation of the uterine lining. This cycle is directed by intricately interacting substances produced by the hypothalamus, pituitary, and ovaries. In order to evaluate research of its relationship to 
taste perception, it is necessary to review physiology of the menstrual cycle.

Structures in the central nervous system regulate the female reproductive cycle. The mid-basal hypothalamus synthesizes and secretes at least one gonadotropic releasing factor. Rate of secretion varies cyclically, but can be affected by external stimuli. This releasing factor is transmitted via the hypothalmic hypophyseal portal vessels to the adenohypophysis of the pituitary. In response, the pituitary releases the gonadotropic neurohormones folliclestimulating hormone (FSH) and luteinizing hormone (LH) . Both of these substances are low molecular weight glycoproteins, and both stimulate ovarian cells by combining with cellular membrane receptors. FSH causes development of vesicular follicles which secrete estrogens. IH is necessary for the formation of the corpus luteum, an ovarian structure which secretes progestins. Small amounts of estrogen and progesterone are also produced by the adrenal cortices.

Estrogens, of which $\beta$-estradiol is the most potent, are steriods synthesized from cholesterol and acetyl coenzyme A. Plasma concentrations vary across the menstrual cycle from $100-750 \mathrm{pg} / \mathrm{ml}$. Estrogen circulates in the blood for only a few minutes before attaching to receptor sites on target tissues. A principal function of estrogen is maturation of the reproductive organs at puberty. In a 
sexually mature female, target tissues for estrogen are the linings and muscular coats of the vagina, uterus, fallopian tubes, and structures in the central nervous system. Systemcally, estrogen increases metabolic rate and promotes sodium and water retention by the kidney.

of the class of progestins, progesterone is most biologically significant. This steroid is synthesized from acetyl coenzyme $A$, in much greater quantities than estrogens. Plasma levels may vary from $1-8 \mathrm{ng} / \mathrm{ml}$ again dependent on phase of menstrual cycle. Progesterone's principal function is to promote secretory activity of the endometrium, and to maintain implantation of a fertilized ovum. Progesterone also acts systemically to increase basal body temperature and enhance sodium and water reabsorption. Both estrogen and progesterone are enzymatically degraded in the liver and excreted in urine (Goodman, 1980; Hainsworth, 1981).

The human menstrual cycle is approximately 28 days in length. Although continuous, it may be divided for experimental purposes into five phases. Levels of ovarian hormones and gonadotropins fluctuate across these phases.

Menstrual phase. In the absence of pregnancy, the highly vascularized uterine lining desquamates. Muscular contractions expel the uterine contents. The menstrual flow lasts from three to seven days; approximately $50 \mathrm{ml}$ of 
blood is lost. Estrogen and progesterone levels at this time are quite low.

Preovulatory phase. About eight days after the onset of menses, FSH stimulates several ovarian follicles to increase in size. Cells within the enlarging follicles secrete estrogen. Estrogen stimulates the uterine endometrial cells to proliferate. In synergistic effect with FSH and a small surge of $\mathrm{LH}$, estrogen causes a single ovarian follicle to begin maturation. From Day 8 to Day 14, plasma levels of estrogen rise to a sharp peak. This inhibits pituitary release of $\mathrm{FSH}$; in response estrogen levels fall rapidy.

Ovulatory phase. At about Day 14, surges of $\mathrm{LH}$ from the pituitary peak. This initiates release of an ovum and the subsequent transformation of the ruptured follicle into a corpus luteum. Progesterone levels begin to increase. Other physiological markers of ovulation are cervical mucorrhea, cytological changes in the cervix, and intermenstrual pain. Basal body temperatures decrease prior to ovulation by .4 to $1.8^{\circ} \mathrm{F}$ (Vollman, 1977).

Luteal phase. The corpus luteum enlarges and continues to secrete progesterone; plasma levels peak at Day 20. Progesterone causes further swelling, proliferation, and secretory activity of the cells of the endometrium. Estrogen produced by the corpus luteum rises gradually to a smaller peak at this same time. Both these hormones exert 
a negative feedback effect on adenohypophyseal release of LH and FSH. The corpus luteum functions for about twelve days.

Premenstrual phase. The corpus luteum degenerates and estrogen and progesterone decrease to levels characteristic of the menstrual phase. The uterine lining involutes as a response to estrogen withdrawal. The pituitary, released from negative feedback effects of the ovarian hormones, again increases output of gonadotropins.

Figure 1 shows the cyclical fluctuations of plasma levels of estrogen and progesterone.

Menstrual Cycle Effects on Taste Perception

Taste sensitivity in human females may co-vary with cyclical changes in estrogen and progesterone levels. Glanville and Kaplan (1965) assessed the effect of menstrual cycle phase on sensitivity to two bitter tastants, propylthiouracil and quinine sulfate. Subjects were tested three times weekly over a period of one or two cycles. Detection thresholds for both stimuli were reduced when subjects were tested during their menstrual phase relative to the premenstrum. Henkin (1974) utilized sodium chloride as a tastant to determine detection and recognition thresholds in five normally cycling women. Subjects were tested every one to three days for six weeks. Daily basal body temperature measurements were carried out to identify time of 
ovulation. Detection acuity for sodium chloride decreased during the luteal phase of the menstrual cycle relative to the follicular (preovulatory) phase.

However, Henkin observed no effect for menstrual cycle on recognition thresholds for sodium chloride. In a longitudinal study over a seven-month period, Pangborn (cited in Hoshishima, 1967) measured taste thresholds for sodium chloride, sucrose, glucose, and citric acid in eight women. No effect for menstrual cycle was found. Beiguelman lcited in Doty, 1978) reported no menstrual cycle phase effect on detection thresholds for the bitter tastant phenylthiourea. More research is needed to determine any effect of menstrual cycle phase on taste sensitivity.

The relationship between female reproductive hormones and the hedonic component of gustation has been studied. Dippel and Elias (1980) compared preferences for four sucrose solutions in human females, under several hormonal conditions. Pregnant women in any trimester selected weaker solutions as most preferred than did nonpregnant women. Women using low progestin potency oral contraceptives preferred stronger concentrations of sucrose than did women using high progestin potency compounds, or women using no oral contraceptive. However, this finding must be interpreted cautiously, since synthetic hormones contained in oral contraceptives vary from each other in biological activity. 


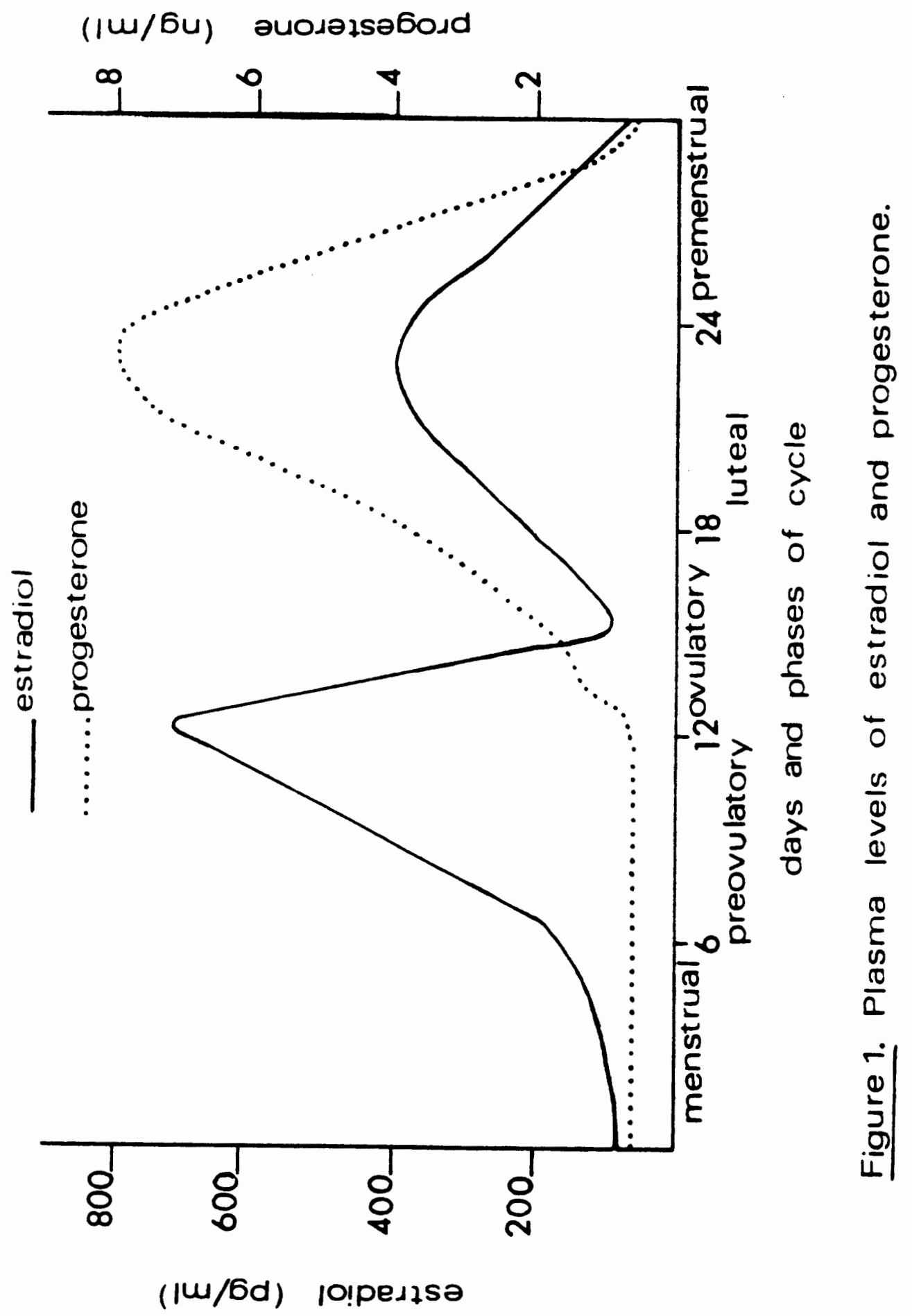


Four studies have examined hedonic response to taste stimuli as a function of menstrual cycle phase (Wright \& Crow, 1973); Aaron, 1975; Pliner \& Fleming, 1983; Weizenbaum, Benson, Solomon, \& Brehony, 1980). All researchers used sucrose as the gustatory stimulus. Three of these studies report significant results.

Wright and Crow (1973) measured 94 normally cycling women's preferences for sucrose. Five concentrations of the stimulus $(2.5,5.0,10,20$, and 408$)$ were rated on a scale from -2 (very unpleasant) to +2 (very pleasant). During a single experimental session, stimuli were rated prior to, 10 minutes after, and one hour after ingestion of a glucose meal. These researchers divided the menstrual cycle into five equal phases--menses, preovulatory, ovulatory, luteal, and premenses. Each subject's cycle phase on the day of testing was determined by self-report of menstrual history. Prior to ingestion of the preload, women presumed to be in luteal phase gave signficantly lower cumulative pleasantness ratings than did women in all other phases. Ratings given by all cycle phase groups decreased following the glucose meal. For women tested at time of ovulation, this negative shift in pleasantness was significantly slower to occur.

Pliner and Fleming (1983) examined 34 normally cycling women and compared preference for sucrose solutions at two phases of the menstrual cycle. Half of the subjects were 
tested at the mid-point of the luteal phase, which was defined to be a 14-day period between ovulation and the onset of menstruation. The remainder were tested at the midpoint of the "follicular" phase; this corresponds to the preovulatory phase defined by other researchers. Subjects fasted overnight before assigning pleasantness ratings to five solutions of sucrose in distilled water $(2.5,5.0,10$, 20, and 408). A five point rating scale from -2 for very unpleasant to +2 for very pleasant was used. Fifteen or 30 minutes following ingestion of a glucose load, subjects were retested with the same stimuli and rating scale. A significant interactive effect was found between metabolic state and phase of cycle. Women tested during luteal phase gave decreased combined pleasantness ratings following a glucose load as compared to ratings following fasting. No such decrease was observed for women tested during the follicular phase. Elapsed time between ingestion of glucose and experimental trials (15 or 30 minutes) was not a significant factor.

Aaron (1975) tested women's hedonic responses to three sucrose solutions $(0.5,1.0$, and 2.0 Molar) following an overnight fast. Of 74 subjects, 39 used oral contraceptives. Subjects rated pleasantness of solutions on a tenpoint scale. Each subject was tested only once. Determination of phase of menstrual cycle at testing was made by analyzing the dates and duration of two previous menstrual 
cycles. An effect of menstrual cycle on sweetness preference was found. Women tested in luteal phase assigned significant lower combined pleasantness ratings than did women tested in the menses or ovulatory pahses.

One group of researchers found no menstrual cycle effect on sweetness preference. Weizenbaum, Benson, Solomon, and Brehony (1980) conducted a longitudinal study of 12 females, with phase of cycle determined by daily basal body temperature recordings as well as by onset and termination of menstrual flow. Trials were carried out five times over a seven week period; the experimental task was to give magnitude estimates of the pleasantness and sweetness of seven sucrose solutions. Neither pleasantness nor sweetness ratings were significantly affected by phase of cycle. Preference data for ovulatory and premenstrual phases were not analyzed, since too few subjects were tested at these times. In a free-feeding test, women in the luteal phase ate more salted peanuts and more chocolate candies than did women in the menses or preovulatory phases.

\section{Statement of Hypotheses}

No research has been reported on hedonic response to sour, bitter, or salty tastes as a function of menstrual cycle phase. This experiment was designed to measure any systematic effect of menstrual cycle on preference for gustatory stimuli. Normally cycling females were randomly 
assigned to one of five groups corresponding to menstrual cycle phases as described previously. Pleasantness ratings were obtained for seven molar solutions of compounds representing each of four primary taste qualities: sweet, sour, salty, and bitter.

It was expected that women tested in luteal phase would produce a different profile of response to sucrose solutions than women tested in other phases. This finding would be consistent with previous reports; a majority confirm a menstrual cycle effect on hedonic response to sweet substances. Other researchers (Wright \& Crow, 1973; Aaron, 1975) found that perceived pleasantness of sucrose is reduced during luteal phase. Since these workers combined all pleasantness ratings for analysis, it was not possible to predict which specific concentrations of sucrose would be least liked.

It was further predicted that hedonic response to sour (citric acid) taste stimuli would be functionally related to phase of menstrual cycle. This hypothesis was based on indirect evidence. Levels of central nervous system activation co-vary with levels of estrogen (Klaiber, Kobayashi, Broverman, \& Hall, 1971). Such fluctuations in general arousal might be expected to affect gustatory sensory functioning.

Klaiber and his co-workers (1971) found that monoamine oxidase (MAO) activity varies in a consistent manner across 
a normal menstrual cycle. MAO is an enzyme that regulates activity at adrenergic synapses in the brain. During the preovulatory phase, estrogen levels are high, MAO levels are low and central adrenergic functioning is enhanced. During the premenses phase, estrogen levels are low, MAO levels are high and central adrenergic functioning is suppressed. When central adrenergic functioning is enhanced, gustatory stimuli might be perceived as more intense. Hedonic response could be indirectly affected; perceived pleasantness of a sour stimulus is known to be inversely related to its perceived intensity (Moskowitz, Kumraiah, Sharma, Jacobs, \& Sharma, 1976). In the present experiment, it was hypothesized that Preovulatory group women would differ from those of Premenses group in their hedonic response to the sour taste stimulus, citric acid.

It was hypothesized that women in luteal phase would choose significantly different pleasantness ratings for solutions of sodium chloride than would women in other phases. This result would be consistent with Weizenbaum's (1980) finding of a menstrual cycle effect on consumption of salted peanuts. Women in luteal phase consumed more during a free-feeding test than did women in some other phases. However, the significant stimulus may have been the peanuts rather than the salt.

A menstrual cycle effect on perceived pleasantness of a bitter tasting substance (quinine) was hypothesized in 
this experiment. This prediction was based on a review of the animal literature. Wade (1976) has observed that rats with high levels of progesterone and low or moderate levels of estrogen show reduced aversion to quinine. Luteal phase women were expected to differ in hedonic response to quinine from women in other menstrual cycle phase groups. 


\title{
CHAPTER II
}

\author{
METHOD
}

\section{SUBJECTS}

Subjects were 102 females, age $18-40$ years (mean age 24.75 years). They were recruited from upper and lower division psychology classes at Portland State University. Some received extra credit from psychology department instructors for their participation. Subjects had normal menstrual cycles; females who were pregnant, lactating, or who used oral contraceptives were excluded. Tobacco smokers were also excluded.

\section{MATERIALS}

Materials were a series of seven solutions of each of four chemical stimuli. Stimuli consisted of deionized water plus commercial grade sucrose $(.01, .023, .046, .10$, $.23, .46$, and $1.0 \mathrm{M})$; sodium chloride $(.01, .02, .04, .09$, $.17, .51$, and $1.0 \mathrm{M})$; reagent-grade citric acid $(.003$, $.007, .01, .02, .05, .10$, and $.50 \mathrm{M}$ ) or quinine monohydrochloride $(.00005, .0001, .00025, .0005, .0015, .005$, and $.015 \underline{M})$. Reagents were weighed on an analytic balance \pm \pm $0.0001 \mathrm{~g})$. Solutions were prepared by the experimenter no 
more than 24 hours before use and were presented at room temperature $\left(22-24^{\circ} \mathrm{C}\right)$.

\section{PROCEDURE}

Subjects were randomly assigned to one of five groups and scheduled for an experimental session according to phase of menstrual cycle. Each subject was tested only once. Trials were conducted between 8:30 am and 7:00 pm. Determination of menstrual cycle phase was done by using self-report of most recent menses. Women assigned to the ovulation group recorded daily basal-body temperatures to establish time of ovulation. Groups were formed according to these criteria: Group I, menses--any day of menstrual flow; Group II, preovulatory--Day Two following cessation of menses to four days prior to ovulation; Group III, ovulatory--basal body temperature reduction observed on two consecutive days; Group IV, luteal--ten to seven days prior to the onset of menses; Group V, premenses--a three-day period which immediately preceeded menstrual flow (Weizenbaum, et al., 1980). Followup phone contacts were used to verify that women in Groups IV and $V$ were tested at the correct time relative to the onset of the following menses.

All subjects took an oral temperature upon awakening on their day of testing. Subjects were instructed not to eat or drink anything other than water for two hours prior to testing. Upon arrival at the laboratory, subjects 
completed an interview on diet, allergies, and menstrual history. Subjects who were on a medically supervised sucrose- or sodium-restricted diet, or who were allergic to citric acid or quinine were excluded from further procedures. Six subjects were thus excluded, so that data are reported for 96 subjects. Remaining subjects signed an informed consent statement and received an explanation of the experimental task.

All taste stimuli were presented as $105 \mathrm{ml}$ paper cups containing $10 \mathrm{ml}$ of a colorless liquid. The subject was instructed to take a sip of the liquid and hold it in her mouth while evaluating it for pleasantness of taste. The subject indicated her judgment by circling a number on a seven-point scale (+1--very unpleasant to +7--very pleasant taste). The subject then expectorated the solution and rinsed her mouth with deionized water until the taste of the stimulus could no longer be detected.

Each subject was first given a practice trial using tap water as a stimulus and then fourteen taste stimuli. Seven solutions of differing molarities of one chemcial were followed by seven concentrations of a different chemical. Half the subjects in each menstrual cycle group were given sucrose and citric acid stimuli; the remainder were given sodium chloride and quinine monohydrochloride stimuli. Order of presentation was randomized within a single taste quality and counterbalanced between taste qualities. 
An assistant to the experimenter assigned code numbers to the stimuli, so that neither the experimenter nor subject were aware of the molarities of solutions as they were presented. Upon completion of the task, each subject was given an explanation of the experiment and her questions were answered. 
CHAPTER III

RESULTS

Taste pleasantness ratings chosen by subjects in each of the five cycle phase groups were totaled and a mean rating obtained for seven molar solutions per taste quality. Each of the four taste qualities was then analyzed separately. A one-way multivariate analysis of variance (Nie, Hull, Jenkins, Steinbrenner, \& Bent, 1975) was used to compare group profiles of hedonic response. This statistical test was selected because it is sensitive to between-group differences in patterns of response to the independent variable. The one-way ANOVA does not require that covariances satisfy the restrictive compound symmetry assumptions made in the standard mixed model repeated measures ANOVA, which might have been used with this research design. Several differences between cycle phase groups were determined to be statistically significant.

Response to Sucrose

A significant overall effect of cycle phase was found for pleasantness ratings assigned to sucrose (sweet) solutions (Wilks' lambda 0.43, $\underline{\mathrm{F}}(4,44)=2.12, \mathrm{p}<.02$ ). However, no single concentration of the stimulus differentiated cycle phase groups. A stepwise discriminant analysis 
was performed to select the most useful set of molarities of sucrose for distinguishing between cycle phase groups. Five concentrations of sucrose acted as discriminating variables; in order of increasing molarity, these were: .023 $\underline{M}, .046 \underline{M}, 0.23 \underline{M}, 0.46 \underline{M}$, and $1.00 \underline{M}$ sucrose. Two concentrations of sucrose, $0.01 \underline{M}$ and $0.10 \underline{M}$ were not significant discriminating variables. Only one significant linear discriminant function was found using the responses to these five concentrations; it accounted for 58.728 of between group variance. Profiles of hedonic response by the cycle phase groups to the discriminating stimulus variables may be seen in Figure 2. The standardized linear discriminant function coefficients for this function are useful in comparing the contribution of each stimulus solution to the significant function (see Table I). The presence of both positive and negative signs in the discriminant function coefficients suggests that cycle phase group differences arise from contrasts in responses to the differing concentrations of the stimulus, rather than from overall differences at all concentrations. A univariate analysis of variance using combined pleasantness ratings assigned to sucrose as the dependent variable was not significant ( $\underline{F}$ ( 4 , $44)=0.77, \mathrm{p}>.201$.

Using Hotelling's $\mathrm{T}^{2}$ tests in pairwise comparisons of cycle phase groups' hedonic responses to sucrose, several statistically significant effects were obtained. Luteal 

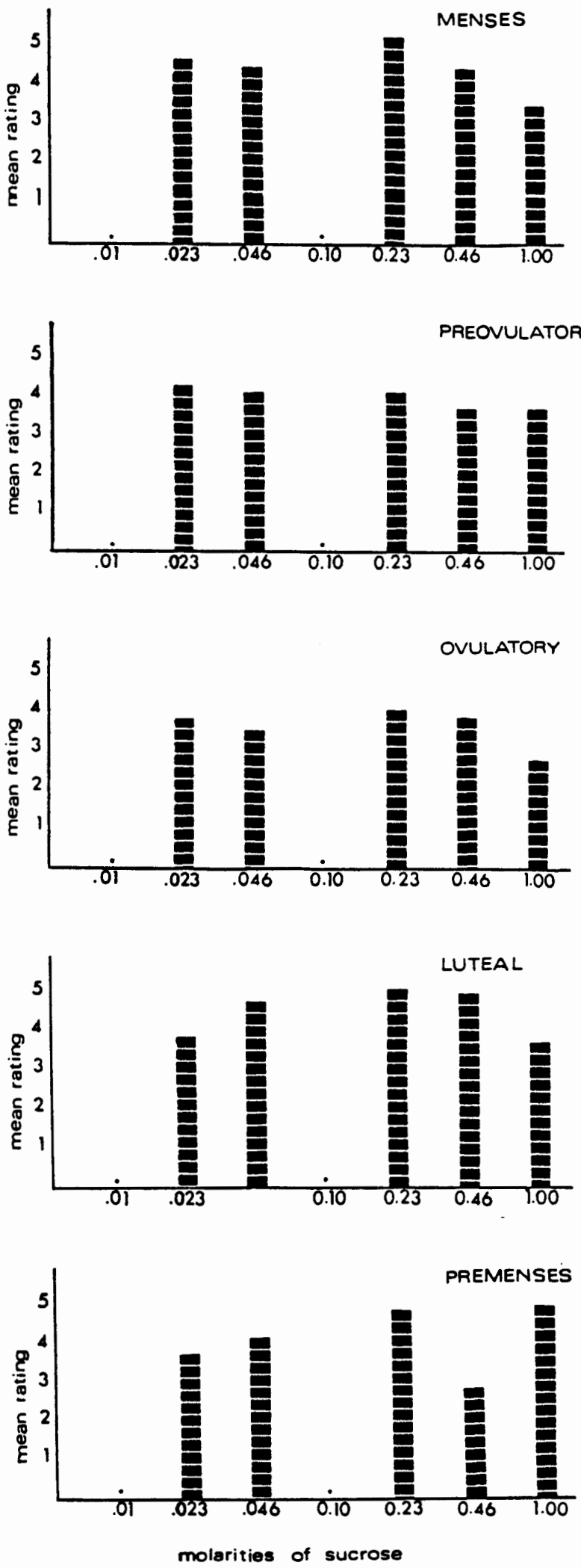

Figure 2. Meen pleasantness ratings assigned to sucrose solutions by manstrual cycle phase groups. 


\section{TABLE I}

\section{COEFFICIENTS OF EACH MOLARITY OF SUCROSE \\ ON THE SIGNIFICANT STANDARDIZED \\ LINEAR DISCRIMINANT FUNCTION}

\section{Molarity of Sucrose}

Standardized Linear Discriminant Function Coefficient
$.01 \underline{M}$
$.023 \underline{M}$
$-0.73$
$.046 \underline{M}$
0.90
$0.10 \mathrm{M}$
$0.23 \underline{M}$
0.31
$0.46 \mathrm{M}$
0.54
$1.00 \mathrm{M}$
$-0.64$

*These molarities did not serve as variables in the significant linear discriminant function. 
group mean ratings differed from those of the Premenses group $(\underline{F}(5,40)=3.58, \mathrm{p}<.01)$ and from those of the Preovulatory group $(\underline{\mathrm{F}}(5,40)=3.78, \mathrm{p}<.01)$.

In Table $I$, it may be seen that discriminant function coefficients assigned to $.023 \mathrm{M}$ and .046 M sucrose are large, and are opposite in sign. Therefore, these two relatively weak solutions are of importance in determining the differences in response profiles produced by the cycle phase groups. Women in both Luteal and Premenses groups found .046 $\underline{M}$ sucrose more pleasant tasting than .023 $\underline{M}$ sucrose. By contrast, women in Menses and Preovulatory groups gave higher pleasantness ratings to $.023 \underline{M}$ sucrose, the more dilute stimulus solution (see Figure 2 ).

Further analysis of the cycle phase groups' responses is suggested by the discriminant function coefficients assigned to the strongest concentrations of sucrose used as stimuli $(0.23 \underline{\mathrm{M}}, 0.46 \underline{\mathrm{M}}$, and $1.00 \underline{\mathrm{M}})$. Table I shows that the coefficient for $1.00 \underline{M}$ sucrose is large, and is opposite in sign, to the coefficient assigned to $0.23 \mathrm{M}$ or 0.46 $\underline{M}$ sucrose. With reference to Figure 2 , it is clear that cylce phase groups significantly differ in their profiles of response to these three stimuli. For example, Luteal and Menses groups' mean pleasantness ratings decreased as concentration of the stimulus increased. However, Luteal group responses to these stimuli were distinctly different from those of Premenses group. Luteal group women rated 
$1.00 \mathrm{M}$ sucrose as less pleasant tasting than $0.46 \mathrm{M}$ sucrose; Premenses group women found $1.00 \mathrm{M}$ sucrose to be more pleasant than a $0.46 \underline{M}$ solution. Preovulatory group women gave equal mean pleasantness rating to $0.46 \underline{\mathrm{M}}$ and $1.00 \underline{\mathrm{M}}$ sucrose.

Response to Citric Acid

Multivariate analysis of variance demonstrated a significant effect of cycle phase on subjects' hedonic responses to citric acid (sour) solutions (Wilks' lambda 0.46, $\underline{F}$ $(4,44)=1.75, \mathrm{p}<.05)$. A univariate analysis of combined pleasantness ratings assigned to citric acid found no significant overall group differences $(\underline{F}(4,44)=2.08, \mathrm{p}$ $>$.10). Interaction between cycle phase and concentration of the stimulus solution produced differing profiles of response. These results appear in Figure 3. Stepwise linear discriminant analysis reveals one statistically significant function which accounts for 71.498 of the variance between cycle phase groups. The function employs five molarities of citric acid as discriminating variables. These are $.003 \underline{\mathrm{M}}, .007 \underline{\mathrm{M}}, 0.01 \underline{\mathrm{M}}, 0.05 \underline{\mathrm{M}}$, and $0.50 \underline{\mathrm{M}}$ citric acid. Two concentrations of this stimulus, $0.02 \underline{\mathrm{M}}$ and 0.10 M citric acid did not serve as discriminating variables. Table II gives the standardized coefficients assigned by the single significant linear discriminant function to each of these concentrations of citric acid. 

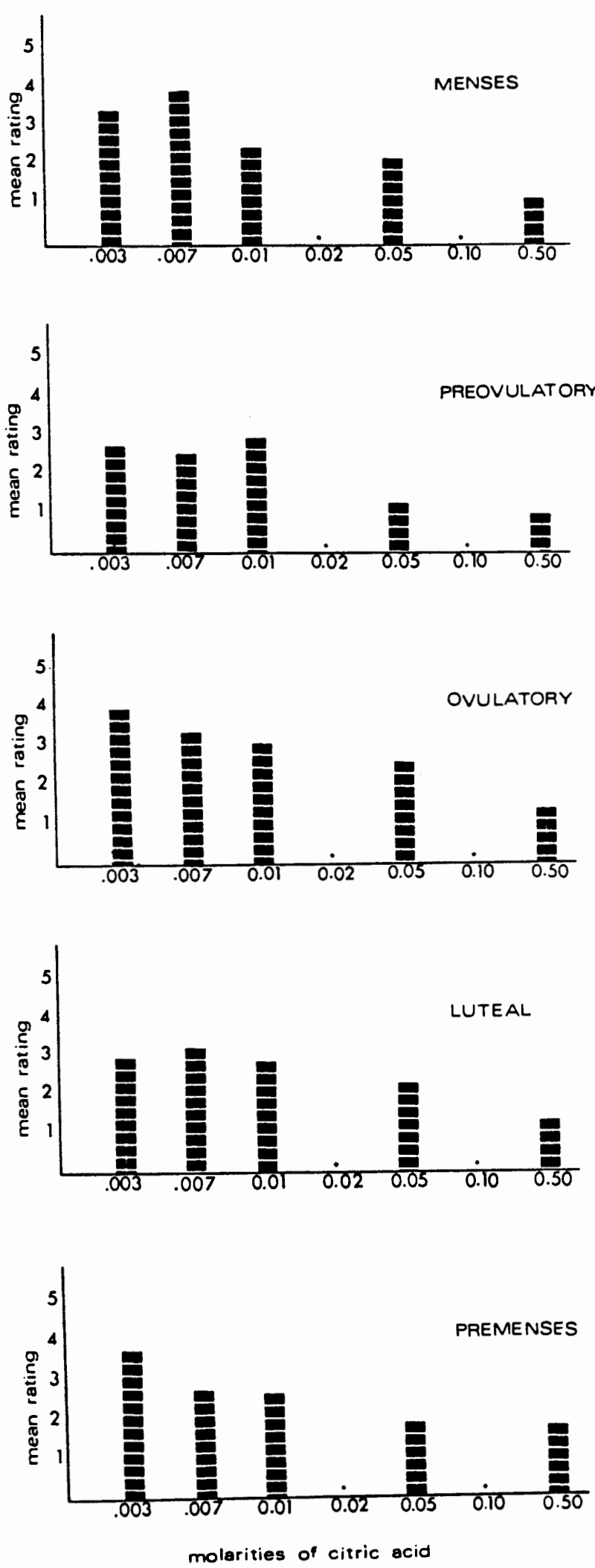

Figure 3. Mean pleasantness ratings assigned to citric acid solutions by menstrual cycle phese groups. 
TABLE I I

COEFFICIENTS OF EACH MOLARITY OF CITRIC ACID ON THE SIGNIFICANT STANDARDIZED LINEAR DISCRIMINANT FUNCTION

Molarity of

Standardized Linear

Citric Acid

Discriminant Function

Coefficient

$\begin{array}{ccc}.003 & \underline{M} & 0.26 \\ .007 & M & 0.60 \\ 0.01 & \underline{M} & -0.84 \\ 0.02 & \underline{M} & \star \\ 0.05 & M & 0.85 \\ 0.10 & \underline{M} & \star \\ 0.50 & \underline{M} & -0.47\end{array}$

*These molarities did not serve as variables in the significant linear discriminant function. 
Hotelling's $\mathrm{T}^{2}$ tests were used to make pairwises comparison of responses to the sour stimulus. Menses group ratings differed significantly from those of Preovulatory group $(\underline{F}(5,40)=4.77, \underline{p}<.002)$ and from those of Premenses group $(\underline{F}(5,40)=2.52, \underline{P}<.05)$. Responses of Preovulatory group also differed from those of Premenses group $(\underline{F}(5,40)=2.72, \mathrm{P}<.05)$.

Table II shows that the linear discriminant function coefficient assigned to 0.01 M citric acid is large and is opposite in sign when compared with coefficients for .003 and .007 M citric acid. This indicates that these three weakest concentrations of the stimulus are of importance in determining the contrasting profiles of response produced by the menstrual cycle phase groups. Figure 3 reveals that pleasantness ratings chosen by women in ovulatory and Premenses groups decreased as concentration of citric acid increased. By contrast, Preovulatory group women exhibited an initial decrease, and then an increase in pleasantness ratings chosen for these three stimuli. Preovulatory group women gave 0.01 M citric acid the highest pleasantness rating of all stimulus solutions.

Further analysis of the menstrual cycle phase groups responses to citric acid is suggested by the discriminant function coefficients assigned to $0.05 \underline{M}$ and $0.50 \underline{M}$ solutions. In Table I it may be seen that the coefficient for $0.05 \underline{M}$ citric acid is larger and is opposite in sign to the 
coefficient for 0.50 M citric acid. With reference to Figure 3 , it may be determined that cycle phase groups are distinct from each other in their profiles of response to these two stronger concentrations of citric acid. For all groups, $0.50 \underline{M}$ citric acid was less pleasant than a $0.05 \underline{M}$ solution. For Menses, Ovulatory, and Luteal groups, this decline in perceived pleasantness is abrupt. However, Premenses and Preovulatory group women selected pleasantness rating for $0.50 \underline{M}$ citric acid that were only slightly lower than those selected for 0.05 M citric acid.

Responses to Sodium Chloride and Quinine

In the multivariate analysis of pleasantness ratings selected for the sodium chloride (salty) stimuli, no overall effect for cycle phase was obtained (Wilks' lambda $0.88, \underline{F}(4,42)=1.40, \mathrm{p}>.20)$. No statistically significant effect of cycle phase was found in response to the quinine (bitter) stimuli (Wilks' lambda $0.84, \underline{F}(4,42)=$ $1.92, \mathrm{p}>.10)$. No signficant linear discriminant functions were found for the salty or bitter taste stimuli. Therefore, no further analysis of these data was carried out. 
CHAPTER IV

\section{DISCUSSION}

The results of the present experiment support the hypothesis that a functional relationship exists between female reproductive hormones and hedonic response to some taste stimuli. Human females tested at different phases of the menstrual cycle exhibited differing profiles of response to seven molar solutions of sucrose. An effect for menstrual cycle phase on profiles of response to citric acid solutions was also obtained. Negative results are reported for responses to sodium chloride and quinine monohydrochloride solution.

\section{Response to Sucrose}

In the present experiment, it was hypothesized that Luteal group would differ from other groups in perceived pleasantness of sucrose solutions. This hypothesis was supported. The profile of hedonic responses to sucrose stimuli produced by Luteal group differed from those produced by Premenses and Preovulatory groups. These group differences resulted from an interaction between menstrual cycle phase and molarity of the stimulus solution. Luteal group did not signficiantly differ from other groups when 
combined pleasantness ratings for all molarities of sucrose were analyzed.

Comparison of Research Outcomes. There have been four previous studies of hedonic response to sucrose as a function of menstrual cycle phase (Wright \& Crow, 1973; Aaron, 1975; Pliner \& Fleming, 1983; Weizenbaum, et al., 1980). Direct comparison between the present research and that done by other workers is difficult. The experiments differ as to concentrations of sucrose used as stimuli, definition of menstral cycle phase, and metabolic state of the subjects at time of testing.

Two studies were unlike the present research in that they measured shifts in hedonic response to sucrose following a glucose preload. Wright and Crow (1973) found that combined pleasantness ratings for five concentrations of sucrose decreased after normally cycling women consumed a glucose meal. For women tested at time of ovulation, this shift was significantly slower to appear. Pliner and Fleming (1983) used a very similar procedure; they reported that a negative hedonic shift following a glucose preload occurred for women tested in luteal phase but not for those tested in preovulatory phase. Observed cycle phase differences in sucrose preference following ingestion of glucose may be due to menstrual cycle related alterations in carbohydrate metabolism (Pliner \& Fleming, 1983). An alternate explanation offered by Wright and crow (1973) is that 
estrogen and progesterone act in the central nervous system to affect gustatory preference. Dissimilar underlying mechanisms may account for menstrual cycle effects on gustatory response in satiated versus fasted subjects.

Aaron (1975) tested subjects who had fasted overnight. He found a menstrual cycle effect on perceived pleasantness of three sucrose solutions $(0.50 \underline{\mathrm{M}}, 1.00 \underline{\mathrm{M}}$, and $2.00 \underline{\mathrm{M}})$. Women presumed to be in luteal phase found these stimuli less pleasant than women in either menses or ovulatory phases. Thirty-nine of 74 subjects were oral contraceptive users, yet no information was provided on the synthetic hormone compostion of the contraceptives. Since true hormonal status of these subjects at time of testing is impossible to determine, this experiment is of little theoretical value.

Weizenbaum and her colleagues (1980) measured perceived pleasantness and sweetness of sucrose to normally cycling women. Weizenbaum's work is of special interest because she reports no menstrual cycle effect on taste hedonics or intensity. This study was methodologically very similar to the present experiment; both used fasted subjects and both defined cycle phase by the basal body temperature method and self-report. Smokers and users of oral contraceptives were excluded as subjects in both studies. Molarities of sucrose used as stimuli were identical. In 
the present experiment, however, a significant result was obtained.

Weizenbaum expresses doubt that sucrose taste hedonics are related to menstrual cycle phase. Menstrual cycle effects obtained in other experiments (Wright \& Crow, 1973; Aaron, 1975) are questionable, because these researchers used only self-report as a means of identifying cycle phase. Since this criticism cannot be applied to the present experiment, another explanation for discrepant outcomes is neccesary. Weizenbaum's group may have obtained an effect for cycle phase had they employed a larger number of subjects. Too few women were tested during ovulatory and premenses phases to permit data analysis. In the present study premenses phase women, who have low circulating levels of estrogen and progesterone, respond differently to sucrose than do women in luteal phase. A menstrual cycle effect on perceived pleasantness of sucrose was supported by the present experiment; Weizenbaum's result was not confirmed.

\section{Response to Citric Acid}

No previous researcher has reported work on hedonic response to a sour stimulus as a function of menstrual cycle variables. In the present experiment, perceived pleasantness of citric acid solutions did vary with menstrual cycle phase. Gonadal hormone-mediated alterations 
in central adrenergic activation were expected to have an effect on gustatory sensitivity. Since perceived pleasantness of a sour stimulus is inversely related to its intensity (Moskowitz, et al., 1976), hedonic response might also be related to central activation. During preovulatory phase, central adrenergic functioning is enhanced relative to the premenstrual phase (Klaiber et al., 1971). It was hypothesized that Preovulatory group women would produce a different profile of hedonic response to citric acid than women in Premenses group. This hypothesis was supported. Premenses group women assigned higher pleasantness ratings to the most concentrated solutions of citric acid than did women in Preovulatory group. In addition, Preovulatory women found these solutions of citric acid to be much less pleasant than those of lower concentration. Premenses group pleasantness ratings decreased as molarity of the stimulus increased, but this decrease was not as abrupt as that of the Preovulatory group. Contrary to expectation, Preovulatory women selected a higher molarity of citric acid as most pleasant than did Premenses women. If Preovulatory women have higher levels of central activation, they might be expected to perceive all molarities of the stimulus as more intense (and less pleasant) than Premenses women. Therefore, these results indicate that perceived pleasantness of citric acid is determined by factors other than level of central activation or arousal. 
Responses to Sodium Chloride and Quinine

No other researcher has published work on preference for salty or bitter tasting compounds relative to the menstrual cycle. Weizenbaum and her colleagues (1980) reported that women in luteal phase ate more salted peanuts during a surreptitious feeding test than did women in other phases. This effect was confined to women whose menses lasted five or fewer days. On this basis, it was hypothesized that Luteal group women would differ from others in their perception of the pleasantness of sodium chloride solutions. This hypothesis was not supported. No menstrual cycle effect on hedonic response to sodium chloride was found in the present experiment. Weizenbaum's subjects' behavior may have been determined by factors other than taste hedonics. Menstrual cycle variables such as level of ovarian hormones are known to affect food intake and body weight regulation (Wade, 1976).

An unexpected finding in the present study was that hedonic response to the bitter stimulus quinine did not significantly differ across menstrual cycle phase groups; this chemical was perceived as unpleasant at every concentration tested. In a review of the animal literature, wade (1976) concluded that rats with low levels of estrogen relative to levels of progesterone show an increased intake of quinine sulfate. It was thus hypothesized that women 
tested in luteal phase, when progesterone levels are highest, would respond differently to quinine monohydrochloride than women in other phases. This hypothesis was not supported. Luteal phase subjects pattern of hedonic response to quinine did not differ from that of any other group. Rodent taste preference data was not useful for predicting human female response to quinine. This may be due to species differences in gustatory or endocrine systems.

Methodological Considerations

A methodological limitation of the present study is that phase of menstrual cycle was defined clinically rather than biochemically. Subjects' circulating levels of estrogen and progesterone at the time of experimental trials were inferred, not directly measured. Therefore, some women may have been assigned to a cycle phase group which did not correspond to their hormonal status. Precise determination of menstrual cycle phase is difficult for several reasons. Normal cycle length is variable within as well as between subjects. A woman's report of her menstrual history may be inaccurate. Detection of ovulation in the present study was done by measure of basal body temperature; however, ovulation may occur without a consequent rise in basal body temperature or may fail to occur (Vollman, 1977). In anovulatory cycles, progesterone levels remain low through the luteal phase and the cycle is shortened. 
Anovulatory cycles have an unknown frequency in clinically normal women. Certainly, radioimmunoassay of gonadal hormones as a means of precisely identifying menstrual cycle phase would have been desirable in the present experiment.

Mechanisms of Gustatory-Endocrine Interaction

Procedures in the present experiment did not permit direct examination of a mechanism by which gonadal hormones could affect gustatory sensory function. Animal researchers have discovered active estradiol and progesterone receptor sites in brain regions involving gustation, such as the ventromedial hypothalamus, olfactory bulbs, and amygdalav (Wade \& Feder, 1972; Pfaff \& Keiner, 1973). It is reasonable to hypothesize that these hormones can alter gustatory function, including the hedonic component of gustation. Theorists agree that estrogens are a primary determinant of hedonic response to sweet tasting substances, and that progestins modulate estrogens' effects. Unresolved issues are these: 1) Does estrogen enhance or depress sweetness preference? 2) Does progesterone behave in a synergistic or antagonistic manner relative to estrogen? and 3) What are the effects of ovarian hormones on hedonic response to bitter, salty, and sour taste stimuli?

Wade (1976) proposes that estrogen enchances preference for sweet tasting substances. Some rodent data are consistent with this view. Adult female rats prefer 
sweeter solutions than do adult males. Female rats show a decline in preference for sweet folowing ovariectomy (Wade \& Zucker, 1969). Progesterone, according to Wade, inhibits estrogen's activity relative to taste responsiveness. In vitro research with human endometrial tissue has shown that progesterone reduces estradiol receptor levels and increases levels of estradiol dehydrogenase, an enzyme that degrades estradiol (Gurpide \& Tseng, 1976).

Dippel and co-workers (1983) argue that estrogen functions to decrease liking for sweet tastes. These researchers noted a decline in sweetness preference of intact female rats when animals were given injections of estradiol. If estrogen enhances liking for sweet tastes, adult females should prefer more concentrated sweet solutions than males. This is true for rodents, but not for humans. Adult human females prefer less concentrated sweet solutions than do adult males. Dippel hypothesizes that progesterone behaves synergistically with estrogen to reduce sweetness preference. Progesterone appears to increase estrogen's effectiveness by detaining it at receptor sites in the hypothalamus (Reuter \& Lisk, 1976).

Some experimental evidence appears to support either Wade's or Dippel's model of gustatory-endocrine interaction. Both of these hypotheses lead to the prediction that preference for sweet tasting compounds will decline when progesterone levels are elevated. Intact female rats given 
exogenous estradiol plus a progestin responded by reducing intake of saccharin; this effect was most prolonged for the strongest progestin used (Dippel, Elias, \& Yandell, 1983). Pregnant and pseudopregnant rats exhibit decreased sweetness preference, as do pregnant human females. Women using high progestin potency oral contraceptives show reduced liking for sweet tastes relative to women using low progestin potency compounds (Dippel \& Elias, 1980). Women tested in luteal phase of the menstrual cycle find sucrose solutions less pleasant than women tested in other cycle phases (Wright \& Crow, 1973; Aaron, 1975).

Other research evidence cannot be adequately explained with reference to Wade's or Dippel's hypotheses. Diminished sweetness preference in ovariectomized rats cannot be restored by giving injections of estrogen or progesterone singularly. Replacement of both hormones is necessary for normal taste responsiveness (Wade \& zucker, 1969). When intact female rats are given injections of progesterone, response to saccharin is not altered (Dippel, Elias, \& Yandell, 1983). Human females using oral contraceptives prefer more concentrated solutions of sucrose than do normally cycling women (Dippel \& Elias, 1980). Results of the present experiment do not fit these simple models of ovarian hormone action on sweetness preference. No overall effect of estrogen and progesterone on combined pleasantness ratings given to a sweet stimulus was obtained. 
Less data is available on ovarian hormone effects on bitter or salty taste responsiveness. Female rats show an aversion to bitter tasting compounds. Ovariectomy reduces this aversion; injection of ovariectomized animals with estrogen and progesterone restores their aversion to quinine (Wade \& zucker, 1970). Intact adult female rats will consume more of 38 sodium chloride solution than will males; this sex difference appears to be due solely to the presence or absence of testosterone during the neonatal period (Křeček et al, 1972). Estrogen and progesterone may act in the brain to reduce the aversive properties of these stimuli. However, the present research outcome does not support a functional relationship between ovarian hormone levels and responsiveness to bitter or salty tastes in humans.

The relationship of estrogen to progesterone, and their co-effects on taste responsiveness are not well understood. Sweetness preference in animals and humans varies with reproductive hormonal status. Accurate prediction of response to a specific taste stimulus is not yet possible. In the present experiment, molar concentration of the stimulus solution was an independent variable. Concentration of the stimulus interacted with phase of menstrual cycle in determining hedonic response to sucrose and to citric acid. Wade's (1976) and Dippel's (1983) models of activity of estrogen and progesterone fail to consider 
this stimulus variable. In all animal literature cited here, a single concentration of a taste stimulus was used. The measure of preference was amount of the stimulus consumed by animals. The combined effects of estrogen and progesterone may be to enhance or to depress sweetness preference, depending upon intensity of the stimulus. Stimulus concentration may be an equally important determinant of gonadal hormone effects on bitter, salty, and sour taste hedonics. Results in the present experiment are consistent with Wade's proposal that gonadal hormones act on neural tissue to alter gustatory response to some stimuli. No direct evidence was provided for a specific mechanism of gustatory-endocrine interaction.

In addition to activity at neural sites, gonadal hormones may affect responsiveness at the gustatory receptor cell level. Puskulian (1972) found that salivary ion composition and flow rates vary with phase of menstrual cycle. Salivary flow rate was lowest during ovulatory phase. Calcium, potassium, and sodium ions in saliva were at lowest concentrations at ovulation. Sodium and potassium ion concentrations were elevated during menses phase. This could alter perceived intensity and pleasantness of some taste stimuli, particularly ionic compounds such as sodium chloride. Henkin (1974) observed that detection acuity for sodium chloride was lower during luteal phase than preovulatory phase. The present research did not find an effect 
on menstrual cycle phase on pleasantness of salty solutions. Menstrual cycle related changes in composition of cells in the oral and nasal cavities have been observed. Richman and Abarbanel (cited in Gandelman, 1983) found that estrogen causes vasocongestion and swelling of the oral mucosa. Gandelman has proposed that gonadal hormones alter gustatory perception via their actions on these tissues.

Menstrual cycle changes in taste responsiveness may not be due to activity of estrogen and progesterone. Other factors which co-vary or interact with gonadal hormones may be determinants of hedonic response to gustatory stimuli. Relationships between hormones and other cyclically fluctuating neuroactive compounds are quite complex. Levels of the pituitary gonadotropins FSH and LH vary across the menstrual cycle, both peaking just prior to ovulation. Production and secretion of gonadotropin releasing factor by the hypothalamus fluctuate cyclically (Goodman, 1980). As previously stated, MAO activity is strongly suppressed by estrogen, while progesterone acts to mildly elevate MAO levels (Klaiber, et al., 1979). Dopamine beta-hydroxylase, an enzyme that catalyzes the neurotransmitter dopamine, peaks soon after ovulation and declines through the luteal phase (Lamprecht, Matta, Little, \& Zahn, 1974). Blankstein and others (1981) found that endorphins vary across the human menstrual cycle and may act in the regulation of $\mathrm{LH}$ secretion. At present, there is no direct human or animal 
evidence that MAO, dopamine beta-hydroxylase, or endorphins bear a functional relationship to gustatory response.

Summary

In the present experiment, an effect of menstrual cycle on perceived pleasantness of some kinds of gustatory stimuli was found. Women tested at five different phases of the menstrual cycle displayed differing profiles of hedonic response to seven solutions of sucrose. A cycle phase effect on profiles of response to seven solutions of citric acid was also shown. When hedonic responses to sodium chloride or quinine monohydrochloride were measured, no functional relationship to menstrual cycle phase was revealed. Further research is necessary to completely describe the relationship between menstrual cycle and taste hedonics. The mechanism by which menstrual cycle variables alter gustatory perception is unknown.

\section{Future Research}

Wade (1976) proposes the use of intracerebral hormone implants to study actions of estrogen and progesterone on neural structures, and subsequent effects on taste preference in rats. However, there is reason to doubt that the rat is an appropriate animal model for study of human gustatory and endocrine function. There are species differences in taste responsiveness. Prepubertal rats of both sexes are indifferent to sweet-tasting substances, while 
human newborns have a strong preference for sweet. Adult female rats prefer more concentrated sweet stimuli than do males; for humans, the opposite is true (Doty, 1978). The reproductive cycle of rodents differs from that of primates as well. Rather than a menstrual cycle, rats have an estrous cycle which lacks a luteal phase. In a review of regulatory mechanisms of the menstrual cycle, cutler and Garcia (1980) stated "It is a serious error to consider the rat as representing a model for the reproductive system of primates such as humans and rhesus monkeys" (p. 90). In his 1976 review, wade reported some evidence that gonadal hormones alter ingestive behavior in non-human primates. The relationship of reproductive variables and taste preference in these animals would appear to be a promising research area.

Replication or expansion of the present experiment would be useful in confirming the effect of menstrual cycle phase on taste hedonics. Identification of cycle phase should be done by plasma level hormonal assay combined with self-report of menstrual history. This would enable more certain conclusions about the roles of estrogen and progesterone to be drawn. Control groups consisting of males, females using oral contraceptives, or post-menopausal females may be appropriate; this issue is discussed in a review by Parlee (1983). 
Work on the possible relationship of endorphins to taste hedonics would be of interest. Endogenous opioids fluctuate across the menstrual cycle (Blankstein, et al., 1981). Perceived pleasantness of taste stimuli could be measured in normally cycling women following injection of naloxone, an opiate antagonist. In future experimentation, stimulus solutions should vary in chemical composition (e.g., sucrose and glucose) and intensity to allow observation of interactive effects. In the present experiment, menstrual cycle effects were limited to stimuli which are innately attractive (sweet) or aversive (sour) to humans. This may be of theoretical importance. Since most evidence favors a menstrual cycle effect on preference for sweet tastes, further experimentation with glucose, lactose, or nonnutritive sweet stimuli would be worthwhile. Such research, if well-designed, would provide additional information on the relationship of menstrual cycle to gustatory response in human females. 
REFERENCES

Aaron, M. (1975). Effect of the menstrual cycle on subjective ratings of sweetness. Perceptual and Motor Skills, $\underline{40}, 974$.

Atkinson, R. L., Atkinson, R. C., \& Hilgard, E. R.

(1983). Introduction to psychology (8th ed.). New

York: Harcourt Brace Jovanovich.

Bailey, E. H. S., \& Nichols, E. L. (1888). The delicacy of the sense of taste. Nature, 37, 557-558.

Beidler, L. M. (1980). The chemical senses: Gustation and olfaction. In V. B. Mountcastle (Ed.), Medical physiology 14th ed.) (pp.586-594). St. Louis: C. V. Mosby.

Blankstein, J., Reyes, F. I., Winter, J. S. D., \& Faiman, C. (1981). Endorphins and the regulation of the human menstrual cycle. Clinical Endocrinology, 14, 287-294.

Carlson, N. R. (1982). Physiology of Behavior (2nd ed.). Boston: Allyn and Bacon.

Coats, A. C. (1974). Effects of age, sex, and smoking on electrical taste threshold. Annals of Otolaryngo$\underline{\operatorname{logy}}, \underline{83}, 365-369$.

Cutler, W. B., \& Garcia, C. R. (1980). The psychoneuroendocrinology of the ovulatory cycle of women: A review. Psychoneuroendocrinology, 5, 89-111.

Desor, J. A., Greene, L. S., \& Maller, O. (1975). Preference for sweet and salty in 9- to 15-year-old and adult humans. Science, 190, 686-687.

Desor, J. A., Maller, O., \& Andrews, K. (1975). Ingestive responses of human newborns to salty, sour, and bitter stimuli. Journal of Comparative and Physiological Psychology, 89, 966-970.

Desor, J.A., Maller, O., \& Turner, R. E. (1973). Taste acceptance of sugars by human infants. Journal of Comparative and Physiological Psychology, 84, 496-501. 
Dippel, R. L., \& Elias, J. W. (1980). Preferences for sweet in relationship to use of oral contraceptives and pregnancy. Hormones and Behavior, 14, 1-6.

Dippel, R. L., Elias, J. W., \& Yandell, L. (1983). Synthetic progestins and sweetness preference in intact female sprague-dawley rats. Physiology and Behavior, 31, 347-351.

Doty, R. L. (1978). Gender and reproductive state correlates of taste perception in humans. In T. E. McGill \& B. D. Sachs (Eds.), Sex and behavior: Status and prospectus (pp. 337-362). New York: Plenum Press.

Fergenson, P. E., Moss, S., Dzendolet, E., Sawyer,F. M., \& Moore, J.W. (1975). The effect of signal probability, food intake, sex, and smoking on gustation, as measured by the theory of signal detection. Journal of General Psychology, 92, 109-127.

Gandelman, R. (1983). Gonadal hormones and sensory function. Neuroscience and Biobehavioral Reviews, 7 , $1-17$.

Glanville, E. V., \& Kaplan, A. R. (1965). The menstrual cycle and sensitivity of taste perception. American

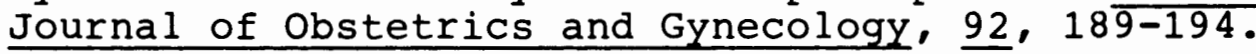

Goodman, H. M. (1980). Reproduction. In V. B. Mountcastle (Ed.), Medical physiology (14th ed.) (pp. 1602-1619). st. Louis: C. V. Mosby.

Greene, L. S., Desor, J. A., \& Maller, O. (1975). Heredity and experience: Their relative importance in the development of taste preference in man. Journal of Comparative and Physiological Psychology, 89, 279-284.

Gurpide, E. \& Tseng, L. (1976). Estrogen in the normal human endometrium. In J. R. Pasqualini (Ed.), Receptors and mechanisms of action of steroid hormones (pp. 109-258). New York: Dekker.

Guyton, A. C. (1976). Textbook of medical physiology (5th ed.). Philadelphia: W. B. Saunders.

Hainsworth, F. R. (1981). Animal physiology: Adaptations in function (pp. 444-488). Reading: Addison-Wesley. 
Henkin, R. I. (1974). Sensory changes during the menstrual cycle. In M. Ferin, F. Halberg, R. M. Richart, \& R. L. Vande Wiele (Eds.), Biorhythms and human reproduction (pp. 277-285). New York: Wiley.

Hoshishima, K. (1967). In M. R. Kare \& O. Maller (Eds.), The chemical senses and nutrition (p. 149).

Baltimore: Johns Hopkins University Press.

Jenkins, J. B. (1983) . Human Genetics. Menlo Park: Benjamin/Cummings.

Klaiber, E. L., Kobayashi, Y., Broverman, D. M., \& Hall, F. (1971). Plasma monoamine oxidase activity in regularly menstruating women and in amenorrheic women receiving cyclic treatment with estrogens and a progestin. Journal of Clinical Endocrinology, 33, 630-638.

Křeček, J. (1973). Sex differences in salt taste: The effect of testosterone. Physiology and Behavior, 10, 683-688.

Křeček, J., Nováková, V., \& Stibral, K. (1972). Sex differences in the taste preference for a salt solution in the rat. Phsyiology and Behavior, $\underline{8}$, 183-188.

Kunka, M., Doty, R. L., \& Settle, R. G. (1981). An examination of intertrial interval and gender influences on sucrose detection thresholds established by a modified staircase procedure. Perception, 10, 35-38.

Lamprecht, R., Matta, R. J., Little, B., \& Zahn, T. P. (1974). Plasma dopamine-beta-hydroxylase (DBH) activity during the menstrual cycle. Psychosomatic Medicine, 36, 304-310.

Moskowitz, H. R., Kumraiah, V., Sharma, K. N., Jacobs, H. L., \& Sharma, S. D. (1976). Effects of hunger, satiety and glucose load upon taste intensity and taste hedonics. Physiology and Behavior, 16, 471-475.

Nie, N. H., Hull, C. H., Jenkins, J. G., Steinbrenner, K., \& Bent, D. H. (1975). Statistical package for the social sciences (2nd ed.). New York: McGraw-Hill.

Pangborn, R. M. (1959). Influence of hunger on sweetness preferences and taste thresholds. American Journal of Clinical Nutrition, $7,280-287$. 
Parlee, M. B. (1983). Menstrual rhythms in sensory processes: A review of fluctuations in vision, olfaction, audition, taste, and touch. Psychological Bulletin, 93, 539-548.

Pfaff, D. W., \& Keiner, M. (1973). Atlas of estradiolconcentrating cells in the central nervous system of the female rat. Journal of Comparative Neurology, 151, 121-158.

Pliner, P., \& Fleming, A. S. (1983). Food intake, body weight, and sweetness preferences over the menstrual cycle in humans. Physiology and Behavior, 30, $663-666$.

Puskulian, L. (1972). Salivary electrolyte changes during the normal menstrual cycle. Journal of Dental Research, 51, 1212-1216.

Reuter, L. A., \& Lisk, R. D. (1976). Progesterone may act at hypothalamus and pituitary by way of enhancement of oestrogen retention. Nature, 262, 790-791.

Rolls, B. J.,Rowe, E. A., \& Rolls, E. T. (1982). How sensory properties of foods affect feeding behavior. Physiology and Behavior, 29, 409-417.

Scherr, S., \& King, K. R. (1982). Sensory and metabolic feedback in the modulation of taste hedonics. Physiology and Behavior, 29, 827-832.

Schwartzbaum, J. S., \& Morse, J. R. (1978). Taste responsivity of amygdaloid units in behaving rabbit: A methodological report. Brain Research Bulletin, $\underline{3}$, 131-141.

Soltan, H. C., \& Bracken, S. E. (1958). The relation of sex to taste reactions. Journal of Heredity, 49 , 280-284.

Vasquez, M., Pearson, P. B., \& Beauchamp, G. K. (1982). Flavor preferences in malnourished mexican infants. Physiology and Behavior, 28, 513-519.

Vollman, R. F. (1977). The phases of the menstrual cycle. In E. Friedman (Ed.), The menstrual cycle: Major problems in obstetrics and gynecology (Vol. 7) (pp. 73-158) • Philadelphia: W. B. Sauders. 
Wade, G. N., \& Feder, H. H. (1972). [1,2-3 H] Progesterone uptake by a guinea pig brain and uterus: Differential localization, time-course of uptake and metabolism, and effects of age, sex, estrogen-priming and competing steroids. Brain Research, 45, 525-543.

Wade, G. N. (1976). Sex hormones, regulatory behaviors and body weight. In J. S. Rosenblatt, R. A. Hine, E. Shaw, \& C. Beer (Eds.), Advances in the Study of Behavior (Vol. 6) (pp. 201-277). New York: Academic Press.

Wade, G. N., \& Zucker, I. (1969). Taste preference of female rats: Modification by neonatal hormones, food deprivation, and prior experience. Physiology and Behavior, 4 , 935-943.

Wade, G. N., \& Zucker, I. (1970). Hormonal modulation of responsiveness to an aversive taste stimulus in rats. Physiology and Behavior, $5,269-273$.

Weizenbaum, F., Benson, B., Solomon, L., \& Brehony, K. (1980). Relationships among reproductive variables, sucrose taste reactivity and feeding behavior in humans. Physiology and Behavior, 24, 1053-1056.

Wright, P., \& Crow, R. A. (1973). Menstrual cycle: Effect on sweetness preference in women. Hormones and Behavior, $\underline{4}, 387-391$. 
APPENDIX 
TASTE STIMULI IN MOLAR AND PERCENTAGE SOLUTIONS

Sucrose $\mathrm{C}_{12} \mathrm{H}_{22}{ }^{\mathrm{O}} 11$

mol. wt. 342.30

\section{Molar}

.01

.023

.046

.10

.23

.46

1.0

15.7

34.2
Percent

.342

.787

1.57

3.42

7.87

Citric Acid

$$
\mathrm{C}_{6} \mathrm{H}_{8} \mathrm{O}_{7} \cdot \mathrm{H}_{2} \mathrm{O}
$$

mol. wt. 210.14
Sodium Chloride NaCl mol. wt. 58.45
Percent

.058

.01

.117

.02

.234

.04

.526

.09

.994

.17

.51

2.98

1.0

5.84
Quinine Hydrochloride

$$
\mathrm{C}_{20} \mathrm{H}_{24} \mathrm{~N}_{2} \mathrm{O}_{2} \mathrm{HCl}
$$

mol. wt. 360.89

\section{Molar}

.003

.007

.01

.02

.05

.1

.5
Percent

.063

.147

.21

.42

1.05

2.10

10.51
Molar

.00005

.0001

.00025

.0005

.0015

.005

.015
Percent .0018

.0036

.009

.018

.054

.180

.541 


\section{PRE-EXPERIMENTAL INTERVIEW QUESTIONS}

1. When did your most recent menstrual period begin?

2. How many days does your menstrual flow usually last?

3. How many days does your mentstrual cycle usually last?

4. Are you on any medically supervised diet?

5. Do you have any medical condition which makes it necessary for you to regulate your intake of sugar or salt?

6. Are you allergic to citric acid (citrus fruits)?

7. Are you allergic to quinine?

8. Did you take your temperature this morning? Was it normal? 
INFORMED CONSENT STATEMENT

, - agree to serve as a subject in the research project investigating taste preference in women conducted by Laurie A. O'Toole.

I understand that this research project will test my preference for certain tastes, and that there are no known physical, psychological, social, economic or legal risks or discomforts. I understand that my participation will not cause any threat to my dignity, invasion of privacy, or inconvenience.

I understand that this study will require 30 minutes of my time.

I have been informed that my responses during the experimental session will remain confidential and that my identity will remain anonymous. After I have finished serving as a subject, I understand that Ms. O'Toole will answer any question I have about my participation and about her research, as long as this does not involve revealing confidential information about any other subjects.

I understand that I am free to withdraw from participation in this study at any time without jeopardizing my relationship with Portland State University or my grade in any course.

If I am presently enrolled in a psychology course, my instructor has explained to me his/her policy concerning extra credit which I may earn by participating in this study.

I have read and understand the above.

If you experience any problems as a result of your participation in this study, please contact the office of Graduate Studies and Research, 105 Neuberger Hall, Portland State University, 229-3423. 


\section{SUBJECT RESPONSE SHEET}

Please circle the number which best describes how PLEASANT the taste of each liquid seems to you. We are interested in your perceptions; therefore, there are no right wrong answers.

\begin{tabular}{|c|c|c|c|c|c|c|}
\hline Practice: & $\begin{array}{c}1 \\
\text { very } \\
\text { unpleasant }\end{array}$ & 2 & 3 & 4 & 5 & 6 \\
\hline
\end{tabular}

A

$\begin{array}{cccccccc}1 & 2 & 3 & 4 & 5 & 6 & \begin{array}{c}7 \\ \text { very } \\ \text { pleasant }\end{array} \\ \text { unpleasant } & & & & & & & \end{array}$

B

1
very
unpleasant

$2 \quad 3 \quad 4$

5

6

7
very
pleasant

C

1

very

unpleasant

23

45

6

7
very
pleasant

D

1
very
unpleasant

$\begin{array}{lll}2 & 3 & 4\end{array}$

5

6
7
very
pleasant

E

1
very
unpleasant

$2 \quad 3 \quad 4$

5

6

7
very
pleasant

F

23

$4 \quad 5$

6

unpleasant

G

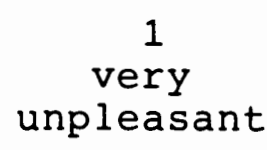

23

4

5

6

7
very
pleasant 